\section{A malquotation}

While thumbing through a backnumber of ET (No 33, Jan 93, p. 36: Kaleidoscope, Dale Roberts) I came across a "serious" mistake. Dale Roberts attributes the coinage of "malquote" to Walter Cronkite. This is not correct. George Orwell, who didn't only enrich our vocabulary with such neologisms as "newspeak", "doublethink", "Thought Police", etc., also coined the word "malquote" in his novel "1984" (p. 41, line 1 , in the Penguin Edition). Dear Mr. Roberts, what's worse than the misquoted "malquote"? Probably petty-minded readers!

Marcus Radi, Aschaffenburg, Germany

\section{Estuary English: a thumbs-down}

Living and teaching in south-east England and surrounded, therefore, by Estuary English, I found David Rosewarne's article in ET37 of particular personal interest. Though it was to be taken as written objectively, I could not help letting out a whoop of joy on reading in it that Estuary English is given the thumbs-down by speakers and learners outside Britain.

The only detail I found strange was Rosewarne's careful description of Estuary English $r$; for while the expert phoneticist might detect small differences, the popular ear judges it, correctly I think, to be so close to $w$ as to make no difference. As one wit has remarked, the TV chat-show personality, Jonathan Ross, would like to describe himself as a "highranking entertainer", but can't.

Objectivity, however, can apply not only to describing a type of English, but also to describing the attitudes of its users; and, whatever the outcome or the standard being aimed at, I think you can

\section{"I" as in imp}

Keep your eye on "I".

It jumps around, wreaks havoc,

Turns run to ruin, trail to trial,

Marital to martial, unite to untie.

Never mind your "P's" and "Q's".

It's "I" that makes the trouble,

Changing deify to defy, and indicting

A judge before inducting him.

Keep "I" tied up lest a rectal Concern become a recital!

Alma Denny, New York

describe someone as trying, or as not trying, to use the language well. I should like to offer, therefore, the following proposition or challenge: that speaking Estuary English is incompatible with trying to speak English well.

If I may, with shameless selfadvertisement, refer to an article of mine in ET31, "Who controls the language?", I suggested there that changes in a language were not neutral and that the health of English might have much to do with the attitudes towards it of its users. In education, there are many subjects in which students are asked to make aesthetic judgements; yet many people, including some language-experts, would wish to exclude the ordinary use of language, and particularly pronunciation, from being considered in that way.

For me, education has much to do with choice; and so I see it as right to encourage pupils to evaluate pronunciation who might not have considered it spontaneously. If, then, the Estuary Eng- lish-speaking pupil decides to continue in all social contexts to say Abbar choo? and Ran a coe na for "How about you?" and "Around the comer", then that must be that; but at least the opportunity and choice would have been explained and offered.

Michael Bulley, Ashford, Kent, England

\section{Reviewing 'the World's First Language'?}

Might it not be time to consider a relaunch of English Today with a more appropriate title, such as The Language Today or Our Language?

Very few people associate the word English with Angeln, where the original English came from. The usual dictionary definition of English is something like "of England". This has never been exclusively true of the language.

Before English had ceased to be spoken on the continent, it was already being spoken in Scotland as well as England. By the twelfth century it was in use in Ireland.

Also by the twelfth century, it had absorbed a huge amount of Norman French. Over the years this hybrid Neo-English has continued to adopt the vocabulary of other languages. The original English element in the language is now much reduced.

The twelfth century was a period of rapid change for the language. The twentieth century will also prove to have been a revolutionary period for the language. It is changing so quickly that older people have difficulty recognising it as the language of their youth. (There is the spread of the glottal stop to sounds other than $/ \mathrm{t}$, e.g. boot and book, now often only distinguishable by the different quality of the vowels, and like and light only by context. 
The development of intervocalic $/ /$ into $/ r /$, e.g. fallen $\rightarrow$ forren; and of final $/ /$ into $/ w /$. The closing of $/ v$ to $/ \mathrm{i}$, so that in is often pronounced een, which is accompanied by the arrival of $\tilde{n}$ for $n$ in words such as campaign, which is often campeñ. In Britain, these features seem to be spreading from London.)

We are increasingly used to people from all round the world speaking the language with great fluency, but with their own accents, making little attempt to sound like Britons or Americans.

We are talking about a language which is hardly "English" in any sense of the word. Perhaps we should be thinking in terms of an English form of The Language, an American form of The Language, an Indian form of The Language, an Australian form of The Language, and so on.

"English" may already have become too ambiguous, and controversial (and inappropriate) a term for what is crucial to worldwide communication. This is a thought which your magazine/ journal - "The International Review of the World's First Language"? - might take on board.

Robert Craig, Weston-super-Mare, Avon, England

\section{'Incorrect' English}

Alec Bristow in his letter 'Pedants versus Parents' fails to recognise that the factors involved in reading and in hearing are different and that ensuring understanding may require different treatments in the two media. My own experience suggests that while an 'incorrect' construction may not hinder comprehension when spoken it can be a confounded nuisance in print. Even the most skilled speakers have been known to change grammatical constructions in mid-sentence, yet the hearers pick up the sense perfectly well; but the same tendency in print can lead to great difficulty for a reader or at the least to some distress through uncertainty.

In the very same issue of English Today is an example confirming my belief, in the interesting article by Revell, Schuh and Moisan on themself and nonsexist style in Canadian legislative drafting. Suppose you are listening to someone saying: "Most people will have a mental image when reading a sex-specific reference that is different than when reading a sex-neutral reference". At the pace of speech, with meaning conveyed as much by stress as by word-content, few would have any difficulty. But I do not think I can be alone in thinking that gathering the meaning off the page at a silent reading pace is hindered by the awkwardness of the construction, by the colloquial rather than strictly necessary future tense, by the agglomeration of the similar words that ... than when, by a clause beginning with that which relates not to its antecedent noun reference but to the more distant image, and by the failure to complete the expected phrase different from.

Some of my fellow-members in the Queen's English Society would call the sentence incorrect; I call it inconsiderate, and hope I might have recast it in the form: "Most people have one mental image when reading a sex-specific reference, and a different one when reading a sex-neutral reference", or, to avoid suggesting that most people's image is the same, and to improve the logical order: "The mental image most people have when reading a sex-specific reference differs from the one they get from a sex-neutral reference".

Lack of attention to the difference between spoken and written language also bedevils the whole article on "An" to "A". As James Drake said, again in your same issue, though on a somewhat different matter: "Let's not carry over principles appropriate for the spoken language into formal written English".

Ted Bell,

Reading, Berkshire, England

\section{Readers' letters are welcomed.}

$E T$ policy is to publish as representative and informative a selection as possible in each issue. Such correspondence, however, may be subjected to editional adaptation in order to make the most effective use of both the letters and the space available.

\section{Poppycock?}

(From 'Perspectives', Newsweek, 24 Jan 94)

'This is political correctness gone mad. You have to wonder where it will all end.'

Allan Robinson of Britain's National Plumbers Association, on a new manual telling plumbers to drop terms such as 'ballcock' and 'stopcock' in favor of the less suggestive 'stop-valve' 